\title{
Pengaruh Disiplin terhadap Kinerja Para Medis Ruang Perawatan Bedah pada RSUD Raden Mattaher Jambi
}

\author{
Azizah $^{1}$ \\ Fakultas Ekonomi Universitas Batanghari ${ }^{1}$
}

\begin{abstract}
The method used in this research is quantitative descriptive method by using statistical formula to help analyze data obtained from the field. The data in this research is obtained by distributing questionnaires to 43 respondents who become the sample. Then processed using Product Moment correlation formula, and assisted with soft ware computer that is SPSS 24 to know there is a relationship between discipline and performance. The result of the research shows that the test regression equation test have positive direction toward employee performance with significant level is proved $t_{\text {count }} 3,893>t_{\text {table }} 2.0195$ in other words have close enough relationship with performance. For a correlation calculation of 0.519 , this indicates a positive relationship between discipline and performance. Furthermore, the determinant coefficient obtained by $27 \%$, the rest of $73 \%$ influenced by other factors outside the study of this study.
\end{abstract}

Keyword: discipline, the performance of the medical

\section{PENDAHULUAN}

Peran manusia dalam organisasi sebagai pegawai memegang peranan yang menentukan karena hidup matinya suatu organisasi tergantung pada pegawai. Pegawai merupakan faktor penting dalam setiap organisasi. Pegawai merupakan faktor penentu dalam pencapaian tujuan organisasi secara efektif dan efisien. Pegawai yang menjadi penggerak dan penentu jalannya organisasi. Sumber daya manusia yang berkualitas dapat diperoleh dari penerapan disiplin yang baik. Pegawai yang disiplin akan memiliki kualitas kerja yang baik pula karena maksud ditumbuhkanna disiplin kerja bertujuan untuk meningkatkan kualitas pegawai. Apabila suatu organisasi ditempati oleh prgawai yang disiplin maka organisasi akan mencapai hasil yang optimal dalam menjalankan kinerjannya.

Kinerja yang baik tidak dapat diperoleh dengan mudah karena semua harus dilakukan dengan kerja keras dan disiplin yang tinggi. Menurut para ahli dalam bidang manajemen dan organisasi mengemukakan berbagai pandangan dan pendekatan untuk menjelaskan mengenai kinerja pegawai. Kirom (2012:51) mengemukan kinerja merupakan suatu standar pekerjaan yang membandingkan tindakan-tindakan khusus dengan sekumpulan kepercayaan, kebijaksanaan, aturan, kebiasaan, serta hal tidak berwujud lainnya yang pada akhirnya disebut sebagai hasil kinerja seorang atau institusi.

Sementara itu menurut Mangkunegara (2006:67) kinerja atau prestasi kerja adalah hasil kerja secara kualitas dan kuantitas yang dicapai oleh seorang pegawai dalam melaksanakan tugasnya sesuai dengan tanggung jawab yang diberikan kepadanya. Kinerja pegawai merupakan hasil dari suatu proses interaksi berbagai faktor seperti: paramedis, laboratorium, sarana prasarana bidang kesehatan, peraturan perundang-undangan di bidang pelayanan kesehatan, dan berbagai input serta kondisi proses lainnya. Berkaitan dengan kinerja berarti seberapa baik seorang pegawai mampu memiliki persyaratan kerja yang ada. Menurut Umar (2013:166) agar pelaksanaan penilaian kinerja dapat dilaksanakan dengan baik maka : (1) Aktivitas ini perlu dipersiapkan dengan sungguh-sungguh, (2) Sistem penilaian harus mempunyai hubungan dengan pekerjaan, (3) memiliki standar- 
standar, (4) menggunakan Nawawi, Hadari, 2011, M ukuran yang dapat diandalkan.

Berkaitan dengan sumber daya manusia menurut Umar (2013:165) ciri karyawan yang memiliki kinerja yang baik yaitu : (1) Cerdas dan dapat berkerja dengan relative cepat, (2) Kompeten secara professional, (3) Kreatif dan Inovatif, (4) Memahami pekerjaan, (5) bekerja dengan cerdik, menggunakan logika, efisien, tidak mudah menyerah dalam pekerjaan, (selalu memberikan perbaikan-perbaikan, tetapi tahu kapan harus berhenti, (7) memiliki catatan prestasi yang baik, (8) dianggap benilai oleh atasannya, (9) selalu meningkatkan diri.

Begitu juga di ruang perawatan bedah pada Rumah Sakit Umum Raden Mattaher Jambi yaitu instansi yang bergerak dibidang kesehatan dan sarana pendidikan. Adapun jumlah para medis Ruang Perawatan Bedah RSU Raden Mattaher Jambi dapat dilihat pada table berikut ini :

Tabel 1. Jumlah Paramedis Ruang Perawatan Bedah Pada RSUD Raden Mattaher Jambi Tahun 2013-2017

\begin{tabular}{ccc}
\hline Tahun & $\begin{array}{c}\text { Jumlah } \\
\text { Pegawai }\end{array}$ & $\begin{array}{c}\text { Persentase } \\
\text { Perkembangan }\end{array}$ \\
\hline 2013 & 42 & - \\
2014 & 43 & 2,33 \\
2015 & 42 & $(2,38)$ \\
2016 & 45 & 0,67 \\
2017 & 43 & \\
\hline
\end{tabular}

Sumber Data: Ruang Perawatan Bedah RSU Raden Mattaher Jambi Tahun 2017

Berdasarkan tabel 1 diatas terlihat bahwa jumlah Paramedis Ruang Perawatan Bedah pada RSUD Raden Mattaher Jambi dalam lima tahun terakhir yaitu: Tahun 2013 Sebanyak 42 orang, tahun 2014 meningkat 43 orang, tahun 2015 meningkat menjadi 42 orang, tahun 2016 terjadi penurunan menjadi 45 orang, tahun 2017 terjadi penurunan paramedis menjadi 43 orang atau $7,14 \%$.
Jumlah Paramedis Ruang Perawatan Bedah pada RSUD Raden Mattaher Jambi cenderung berfluktuasi dikarenakan kuota dari Pemerintah yang terus mengalami penambahan dengan alasan khususnya bagian Ruang Perawatan Bedah ini membutuhkan tingkat pelayanan yang ekstra, tetapi pada tahun 2017 mengalami penurunan menjadi 43 orang dikarenakan adanya paramedis yang pindah. Jumlah paramedis yang cukup banyak terkadang masih terdapat protes dari keluarga pasien.

\section{Identifikasi Masalah}

Sebagai suatu organisasi publik, maka keberadaan RSUD Raden Mattaher Jambi harus memiliki kinerja yang baik, kinerja organisasi pada dasarnya sangat ditentukan oleh kinerja individu. Tuntutan ini agaknya tidak berlebihan, mengingat seringkali ditemui rumah sakit milik pemerintah kurang mengedepankan pelayanan sebagai cerminan masih kurang optimalnya kinerja pegawai. Hal ini suatu fakta yang berdasarkan pengamatan tidak hanya oleh penulis sendiri, akan tetapi oleh masyarakat yang pernah menerima pelayanan kesehatan dari rumah sakit milik pemerintah Provinsi Jambi tersebut. OlehkarenaituRumah Sakit Daerah Raden Mattaher Jambi harus terus membenahi diri dengan meningkatkan kinerja organisasi melalui upaya peningkatan kinerja tenaga paramedis. Kinerja paramedis yang belum optimal akan menyebabkan timbulnya ketidakpercayaan masyarakat.

Dari pengamatan yang penulis lakukan selama ini ternyata masih ada masalah yang terjadi berkaitan dengan kinerja paramedis di ruangperawatanbedahpadaRSUD Raden Mattaher Jambi,terlihat antara lain dari hasil pencapaian kegiatan yang di kemudian dibandingkan dengan target yang telah ditetapkan sebelumnya. Hasil pencapaian program dapat dilihat pada tabel di bawah ini: 
Tabel 2. Target Kerja ruang perawatan bedah pada

RSUD Raden Mattaher Jambi tahun 2013-2017

\begin{tabular}{|c|c|c|c|c|c|}
\hline No & Sasaran & Indikator Sasaran & $\begin{array}{l}\text { Rencana } \\
\text { Tingkat } \\
\text { Capaian } \\
\text { (Target) }\end{array}$ & $\begin{array}{l}\text { Persentase } \\
\text { Rencana } \\
\text { terRealisasi }\end{array}$ & $\begin{array}{c}\text { Persentase } \\
\text { Rencana } \\
\text { yang blm } \\
\text { Ter Realisas }\end{array}$ \\
\hline 1 & $\begin{array}{ll}\text { Terpenuhinya } & \text { alat } \\
\text { kesehatan Medis dan } \\
\text { non Medis. }\end{array}$ & $\begin{array}{l}\text { Tersedianya peralatan } \\
\text { kedokteran umum, } \\
\text { bedah, kardiologi, } \\
\text { internis, non medis } \\
\text { seperti komputer AC } \\
\text { dll, serta peralatan } \\
\text { perawatan dasar } \\
\text { rumah sakit }\end{array}$ & \begin{tabular}{l}
\multicolumn{1}{c}{$100 \%$} \\
Peralatan \\
kedokteran 10 \\
unit \\
Peralatan non \\
medis masing- \\
masing 15 unit
\end{tabular} & \begin{tabular}{l}
\multicolumn{2}{c}{$90 \%$} \\
Yang terealisasi \\
9 unit \\
Terealisasi \\
masing- \\
masing13 unit
\end{tabular} & $\begin{array}{c}\text { Tidak } \\
\text { terealisasi }\end{array}$ \\
\hline 2 & $\begin{array}{ll}\text { Terpenuhinya } & \text { obat- } \\
\text { obatan bahan } & \text { habis } \\
\text { pakai } & \end{array}$ & $\begin{array}{l}\text { Terlaksananya } \\
\text { pemberian pelayanan } \\
\text { pasien Operasi dan } \\
\text { rawat inap }\end{array}$ & $\begin{array}{l}\qquad 100 \% \\
\text { Pemberian } \\
\text { pelayanan } \\
\text { optimal pada } \\
\text { seluruh pasien }\end{array}$ & $\begin{array}{c}90 \% \\
\text { Tereliasi }\end{array}$ & $\begin{array}{l}10 \% \\
\text { Tidak } \\
\text { terealisasi }\end{array}$ \\
\hline 3 & $\begin{array}{l}\text { Terlaksananya penataan } \\
\text { dan pengembangan } \\
\text { SDM berdaya saing }\end{array}$ & \begin{tabular}{l}
\multicolumn{2}{l}{ Tersusunnya } \\
perangkat peraturan \\
kepegawaian yang \\
kondusif r bagi \\
pengembangan SDM
\end{tabular} & \begin{tabular}{l}
\multicolumn{1}{c}{$100 \%$} \\
Semua \\
penataan, \\
peraturan dan \\
pengembangan \\
SDM pegawai \\
dikondusfkan
\end{tabular} & \begin{tabular}{l}
\multicolumn{2}{c}{$85 \%$} \\
Terealisasi \\
hanya pada \\
penataan dan \\
peraturan \\
kepegawaian
\end{tabular} & $\begin{array}{l}15 \% \\
\text { Tidak } \\
\text { terealisasi }\end{array}$ \\
\hline 4 & $\begin{array}{l}\text { Terpeliharanya sarana } \\
\text { dan prasarana ruang } \\
\text { perawatan bedah RSUD } \\
\text { Raden Mattaher Jambi }\end{array}$ & $\begin{array}{l}\text { Terpeliharanya } \\
\text { perangkat sarana dan } \\
\text { prasarana }\end{array}$ & $\begin{array}{l}100 \% \\
\text { Semua terawat } \\
\text { dengan baik }\end{array}$ & $\begin{array}{c}95 \% \\
\text { Ada perangkat } \\
\text { yang harus } \\
\text { diperbaiki }\end{array}$ & $\begin{array}{c}\text { Tidak } \\
\text { terealisasi }\end{array}$ \\
\hline
\end{tabular}

Sumber : RSUD Raden Mattaher Jambi 2017

Berdasarkan Tabel 2 di atas, terlihat bahwa terjadi kesenjangan antara target dan pencapaian kegiatan program RSUD Raden Mattaher Jambi. Data yang ditampilkan pada tabel tersebut adalah merupakan hasil representatif terhadap kinerja paramedis ruang perawatan bedah pada RSUD Raden Mattaher Jambi dimana ada empat program yang dicanangkan oleh RSUD Raden Mattaher Jambi terdapat program yang belum begitu optimal dimana pada sasaran terpenuhinya alat kesehatan medis dan non medis yaitu terrealisasi $90 \%$, pada sasaran terpenuhinya obat-obatan bahan habis pakai yaitu terrealisasi 90\%, terlaksananya penataan dan pengembangan SDM berdaya saing yang terlealisasi $85 \%$, dan terpeliharanya sarana dan prasarana RSUD Raden Mattaher Jambi terrealisasi 95\%. Hal tersebut mempengaruhi kinerja dari organisasi.

Penelitian ini secara mendasar ingin mengetahui pengaruh Disiplin terhadap kinerja Paramedis. Tujuan spesifik dari penelitian ini diungkapkan sebagai berikut:

1. Untuk mendeskripsikan disiplin dan kinerja paramedic Ruang Perawatan Bedah pada RSUD RadenMattaher Jambi

2. Untuk menganalisis pengaruh Disiplin terhadap kinerja paramedic Ruang Perawatan Bedah pada RSUD Raden Mattaher Jambi

\section{TinjauanPustaka}

\section{Disiplin}

Menurut Simamora (2006:610) disiplin adalah prosedur yang mengoreksi atau menghukum bawahan karena melanggar peraturan atau prosedur. Disiplin merupakan bentuk pengendalian diri karyawan pelaksanan yang teratur dan menunjukan tingkat kesungguhan tim kerja dalam organisasi. Menurut Hasibuan (2007: 193) berpendapat bahwa kedisiplinan adalah kesadran dan kesedian seseorang 
mentaati semua perturan perusahaan dan norma-norma sosial yang berlaku. Kedisiplinan harus ditegakkan dal suatu organisasi perusahaan. Tanpa dukungan disiplin karyawan yang baik, sulit bagi perusahaan untuk mewujudkan tujuannya karena disiplin merupakan kunci keberhasilan suatu perusahaan dalam mencapai tujuannya.

Tindaka disiplin dapat pula membantu karyawan agar menjadi lebih prduktif, dengan demikian mengguntungkannya dalam jangka waktu panjang. Tindakan disiplin dapat pula bermakna kualitas yang berharga bagi individu agar tugas dan kinerja yang dihasilkan dapat optimal. Menurut Hasibuan (2007:195), indikator disiplin kerja adalah :

1. Memenuhi semua peraturan perusahaan atau organisasi.

2. Penggunaan waktu secara efektif.

3. Tanggung dalam pekerjaan dan tugas

4. Tingkat absensi.

Faktor-faktor yang menjadi penyebab ketidak disiplinan menurut Hasibuan (2007:195) adalah sebagai berikut :

1. Tujuan dan kemampua

Selain harus menunjang tujuan, maka kedisiplinan yang hendak ditegakkan tersebut haruslah sesuai dengan kemampuan para pegawai.

2. Teladan pemimpin

Untuk lebih mengefektifkan peraturan yang dikeluarkan dalam rangka menengakkan kedisiplinan perlu adanya teladan pimpinan.

3. Balas jasa

Balas jasa (gaji dan kesejahteraan) ikut mempengaruhi kedisiplinan pegawai karena balas jasa akan memberikan kepuasan dan kecintaan pegawai terhadap organisasi.

4. Keadilan

Keadilan ikut mendorong terwujudnya kedisiplinan pegawai. Sifat ego dan sifat manusia yang selalu merasa dirinya penting dan meminta diperlakukan sam dengan manusia lainnya.

5. Pengawasan melekat
Pengawasan melekat adalah tindakan nyata dan paling efektif dalam mewujudkan kedisiplianan pegawai, karena dengan pengawasan melekat ini berarti atasan harus efektif dan langsung mengawasi perilaku, moral, sikap, gairah kerja dan prestasi bawahannya.

6. Sanksi hukum

Untuk menegakkan kedisiplinan perlu adanya sanksi bagi mereka yang mau melakukan indisipliner.

7. Ketegasan

Jangan sampai membiarkan pelanggaran yang diketahui tanpa suatu tindakan atau membiatkan pelanggaran terjadi berlarut-larut tanpa tindakan tegas.

\section{Kinerja}

Menurut Simamora(2006:409) kinerja merupakan tingkat karyawan mencapai persyaratan mencapai pekerjaan. Fahmi (2013:127) mengatakan kinerja adalah hasil yang hasil yang diperoleh oleh suatu organisasi tersebut bersifat profit oriented dan non profet oriented yang dihasilkan selama satu periode waktu.

Sedangkan instrumen pengukuran kinerja yang disampaikan oleh Lembaga Administrasi Negara (2008:282), substansi instrumen pengukuran kinerja terdiri dari aspek-aspek yang berpegaruh terhadap kualitas pelayanan tugas, meliputi :

1. Inovasi

2. Teamwork atau kerjasama

3. Kecepatan kerja

4. Keakuratan kerja

5. Pelayanan.

\section{Hipotesis}

Berdasarakan rumusan masalah dan tujuan penelitian, maka hipotesis dalam penelitian ini adalah sebagai berikut :

1. Diduga disiplin paramedic ruang perawatan bedah pada RSUD Raden Mattaher Jambi cukup tinggi.

2. Diduga disiplin berpengaruh terhadap kinerja paramedic ruang perawatan bedah pada RSUD Raden Mattaher Jambi. 


\section{METODE PENELITIAN}

\section{Analisis Deskriptif}

Analisis deskriptif ini merupakan suatu analisis yang menguraikan atau mendiskripsikan data hasil penelitian tanpa melakukan pengujian. Beberapa teknik yang digunakan untuk mendiskripsikan data hasil penelitian adalah dengan analisis secara deskripsit ini , peneliti menggunakan software SPSS 24.

\section{Uji Analisis}

Analisis regresi linier sederhana yaitu untuk melihat analisis pengaruh motivasi kerja terhadap kinerja paramedic ruang perawatan bedah pada RSUD Raden Mattaher dengan rumus:

$$
\mathrm{Y}=a+b X+e
$$

dimana:

$$
\begin{aligned}
\mathrm{Y} & =\text { Kinerja Pegawai } \\
\mathrm{X} & =\text { MotivasiKerja } \\
a & =\text { konstanta } \\
\mathrm{e} & =\text { Error }
\end{aligned}
$$

$$
R 2=1-\frac{(N-K-1) S_{Y}^{2} \cdot 12 \ldots K}{(N-1) S_{Y}^{2}}
$$

Kriteria uji signifikan ini adalah:

- Jika t hit $\geq \mathrm{t}$ tabatau Sig. $<\alpha(0,05)$, maka Ho ditolak dan Ha diterima.

- Jika $t$ hit <t tabatau Sig. $>\alpha(0,05)$, maka Ho diterima dan Ha ditolak.

\section{HASIL DAN PEMBAHASAN}

\section{Pengujian Hipotesis \\ Uji $t$}

Setelah diketahui hasil yang diperoleh signifikan, maka dilakukan uji t yaitu untuk mengetahui signifikansi konstanta dan signifikan setiap variable bebas. Dengan rumus:

dimana:

$\mathrm{b}=$ Kemiringan garis regresi

$\mathrm{S}_{\mathrm{b}}=$ Kesalahan standar atas koefisien regresi

$$
t_{h i t}=\frac{b}{S_{b}}
$$

\section{Koefisien Determinasi $\left(R_{2}\right)$}

Koefesien determinasi ini berguna untuk menentukan besarnya proporsi sumbangan seluruh variabel bebas (X) terhadap variabel terikat (Y) (Supranto, 2004:58), dengan rumus:
Analisis pengaruh disiplin terhadap kinerja paramedis ruang perawatan bedah pada RSUD Raden Mattaher Jambi.

Penelitian ini menggunakan Alat Analisis Regresi Linear Sederhana dengan

\begin{tabular}{|c|c|c|c|c|c|}
\hline \multirow[b]{2}{*}{ Model } & \multicolumn{2}{|c|}{ Unstandardized Coefficients } & \multirow{2}{*}{$\begin{array}{c}\text { Standardized Coeffients } \\
\text { Beta }\end{array}$} & \multirow[b]{2}{*}{$\mathrm{T}$} & \multirow[b]{2}{*}{ Sig } \\
\hline & $\mathrm{B}$ & Std. Error & & & \\
\hline 1 (Constant) & 1,942 & ,552 & & 3,518 &, 001 \\
\hline Disiplin & ,512 &, 131 &, 519 & 3,893 &, 000 \\
\hline
\end{tabular}
menggunakan Software Statistical Product and Service Solution (SPSS) 24, diperoleh persamaan regresi sebagai berikut :

Tabel 3

Hasil Perhitungan SPSS

Coefficients $^{\mathrm{a}}$

a. Dependent Variable : Kinerja

Dari hasil persamaan regresi linear sederhana dan dari hasil perhitungan SPSS versi 24 menunjukan persamaan $\mathrm{Y}=1,942$ $+0,512 \mathrm{X}+\mathrm{e}$, dari persamaan regresi diatas dapat disimpulkan bahwa nilai konstanta (a) adalah 1,942 artinya jika disiplin kerja bernilai 0 (nol) maka kinerja bernilai positif yaitu 1, 942. Dan untuk nilai koefisien variabel disiplin kerja bernilai positif yaitu 0,512 artinya jika disiplin 
meningkat sebesar $1 \%$ maka kinerja paramedis ruang perawatan Bedah pada
RSUD Raden Mattaher Jambi meningkat sebesar 0,512 atau 51,2\%.

Tabel 4

Model Summary

\begin{tabular}{|c|c|c|c|c|}
\hline Model & $\mathrm{R}$ & R Square & $\begin{array}{l}\text { Adjusted R } \\
\text { Square }\end{array}$ & $\begin{array}{l}\text { Std. Erroe of the } \\
\text { Estimate }\end{array}$ \\
\hline 1 &, $519^{\mathrm{a}}$ &, 270 & 252 & ,22982 \\
\hline
\end{tabular}

a. Predictors: (Constant), Disiplin

Koefisien korelasi dapat dilihat dari tabel diatas bahwa diketahui $\mathrm{R}=0,519$ artinya terdapat hubungan yang erat antara variabel disiplin terhadap kinerja para medis ruang Perawatan Bedah pada RSUD Raden Mattaher Jambi sebesar 0,519 atau sebesar 51,9 \%. Koefisien determinan diketahui dari $\mathrm{R}^{2}$ yaitu 0,270 artinya variabel disiplin mempengaruhi kinerja para medis ruang bedah pada RSUD Raden Mattaher sebesar 0,270 atau hanya sebesar $27 \%$ sedangkan $73 \%$ dipengaruhi oleh variabel-variabel lain yang diteliti.

Untuk uji hipotesa uji t didapat hasil perhitungan $t_{\text {tabel }}$ menggunakan ketentuan berikut: $\mathrm{a}=0,05(5 \%)$ dan Degree of Freedom $(\mathrm{DF})=43-1-1=41$ yaitu $\mathrm{t}_{\text {tabel }}=$ 2,0195 Berdasarkan hasil perhitungan dengan menggunakan program SPSS diperoleh angka $t_{\text {hitung }} 3,893>2,0452$. Berdasarkan hasil tersebut maka Ho ditolakdan $\mathrm{H} 1$ diterima dan dengan membandingkan tingkat signifikan sebesar 0,05 maka $0,000<0,05$ berarti ada pengaruh yang signifikan antara disiplin terhadap kinerja para medis ruang perawatan bedah padaRSUD Raden Mattaher Jambi.

\section{SIMPULAN}

Berdasarkan pembahasan sebelumnya dapat ditarik kesimpulan bahwa hasil perhitungan SPSS versi 24 menunjukan persamaan $\mathrm{Y}=1,942+0,512 \mathrm{X}+\mathrm{e}$, dari persamaan regresi diatas dapat disimpulkan bahwa nilai konstanta (a) adalah 1,942 artinya jika disiplin kerja bernilai 0 (nol) maka kinerja bernilai positif yaitu 1, 942. Dan untuk nilai koefisien variabel disiplin kerja bernilai positif yaitu 0,512 artinya jika disiplin meningkat sebesar $1 \%$ maka kinerja paramedis ruang perawatan Bedah pada RSUD Raden Mattaher Jambi meningkat sebesar 0, 512 atau 51,2\%. Koefisien korelasi yaitu, $\mathrm{R}$ bernilai 0,519 artinya disiplin paramedis ruang perawatan bedah pada RSUD Raden Mattaher Jambi memiliki hubungan yang positif terhadap kinerja yaitu sebesar 0,519 atau 51,9\% sedangkan $\mathrm{R}^{2}$ bernilai 0,270 yang artinya bahwa setelah adanya penyesuaian variabel disiplin berpengaruh terhadap kinerja sebesar 0,270 atau $27 \%$ dan $73 \%$ dipengaruhi oleh variabel-variabel lain yang tidak diteliti dalam penelitian ini.

\section{DAFTAR PUSTAKA}

Bangun, Wilson, 2012, Manajemen Sumber Daya Manusia, Erlangga, Jakarta

Hasibuan, Malayu SP, 2009, Manajemen Sumber Daya Manusia, Penerbit Bumi Aksara, Jakarta.

Handoko, T. Hani 2010, Manajemen Personaliadan Sumber Daya Manusia, BPFE, Jakarta.

Kirom, 2012, Sumber Daya Manusia, Penerbit Bumi Aksara, Jakarta

Mangkunegara, Anwar Prabu. 2005, Evaluasi Kinerja, PT. Refika Aditama Bandung.

Nawawi, Hadari, 2011, Manajemen Sumber Daya Manusia, Gajah Mada University Press, Yogyakarta

Riduan. 2008. Skala Pengukuran Variabelvariabel Penelitian. Bandung. CV. Alfabeta.

Rosidah, 2009, Manajemen Sumber Daya Manusia, Gramedia Pustaka Utama, Jakarta.

Saydam, Gouzali, Drs, Bc.TT, 2005, Manajemen Sumber Daya Manusia, Cet.3, Jakarta. Djambatan. 
Sudjana, 2006. Metode Penelitian Statistika. Bandung. PustakaSetia.

Sugiono. Prof. Dr. 2011, Metode Penelitian Kuantitatif Kualitatif dan $R \& D$, Edisi 1. Bandung. Alfabeta

Suyoto, Danang, 2013, Perilaku Organisasi, CAPS (Center For Academic Publishing Sevice,) Yogyakarta

Umar, Husein, 20013, Riset Sumber Daya Manusia, Gramedia Pustaka Utama, Jakarta. 